\title{
Accentuation of Pulsatile Flow Artifact
}

National Cancer Institute

\section{Source}

National Cancer Institute. Accentuation of Pulsatile Flow Artifact. NCI Thesaurus. Code C86999.

An artifact resulting in ghost images of a vessel extending across the image in the phase encoding direction. 